\title{
Exercise Program for Covid-19 Survivors: A Telerehabilitation Framework
}

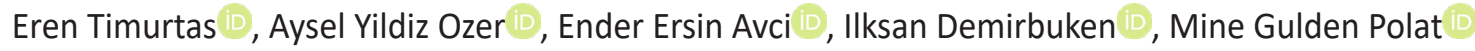 \\ Marmara University, Health Science Faculty, Department of Physiotherapy and Rehabilitation, Maltepe, Istanbul, Turkey \\ Correspondence Author: Ender Ersin Avci \\ E-mail: ender.ersin.avci@gmail.com
}

Received: $01.08 .2020 \quad$ Accepted: 22.05 .2021

\begin{abstract}
Coronavirus disease (COVID-19) is a serious acute respiratory syndrome that has been recognized as a pandemic disease caused by Coronavirus 2 (SARS-CoV-2). The complications related to coronavirus itself, physically inactive period due to symptoms of disease and lockdown may also influence the functional capacities of COVID-19 survivors negatively. It may lead to obstructions in engaging with previous activities of daily living. As a physiotherapy intervention, exercise treatment is one of the novel approaches to support these individuals after the COVID-19 treatment. However, there is limited access to physiotherapy and rehabilitation services during pandemic conditions because of lockdown, especially for infected patients. For increasing accessibility to physiotherapy and rehabilitation care, the World Confederation of Physical Therapy has published a report advising the home-based exercise interventions via Telerehabilitation. Up to date, there is no published framework for structured exercise programs for this population, yet. Since the individual differences in functional levels and possible differences in the severity of coronavirus infection, the physiotherapy, and rehabilitation exercise program should be structured individually for COVID-19 survivors. This document suggests a framework for physical therapists to put into practice an exercise training via telerehabilitation in COVID-19 survivors. The proposed framework has consisted of determination of eligible and risky COVID-19 patients for intervention, physiotherapy assessment tools, 6-week exercise prescription based on FIIT-VP principle (frequency, intensity, time, type, volume, and progression) and criteria for ending exercise.
\end{abstract}

Keywords: COVID-19, Telerehabilitation, Exercise.

\section{INTRODUCTION}

COVID-19 disease, an infection caused by severe acute respiratory syndrome Coronavirus 2 (SARS-CoV-2), was firstly reported in the world on 31 December 2019. COVID-19 contamination occurs easily with contact respiratory droplets, via contact with infected persons, or contaminated objects and surfaces $(1,2)$. The average incubation period of the infection varies between 2-14 days (3).

Up to end of July 2020, 216 countries, areas or territories affected by COVID-19 pandemic with more than 15 million infected cases worldwide have been reported by the World Health Organization. Turkey is one of the most affected countries in the world with the number of 227,982 infected cases (4). While $80 \%$ of people with COVID-19 virus have mild to moderate disease-specific symptoms, $6.1 \%$ of patients require treatment in the intensive care units (5). Among these cases, 210,400 have recovered and 5,600 have died by the fatality rate of $2,48 \%$ in Turkey (4).
After recovery COVID-19 survivors face multifarious health problems. Although the nature of the disease and its long terms effects still require further research, various system involvement including respiratory, cardiac, neurological, muscular systems has been well highlighted by scientific researches $(6,7,8)$. Musculoskeletal system affected by acute peripheral and respiratory skeletal muscle dysfunction accompanied by polyneuropathy and myopathy (8). These activations together result in decreased muscle strength, limited physical activity, impaired functional performance. As a consequence, COVID-19 survivors may suffer from poor quality of life.

Especially the patients who had received the treatment in an intensive care unit have a greater risk of long-term complications. Patients with older age than 65 years old, with comorbidities, having more than 7 days' length of stay in the intensive care unit, and history of mechanic ventilation are considered to be major risk factors related 
to disability and poor quality of life. Besides complications related to coronavirus itself, a physically inactive period due to symptoms of the disease and lockdown may also influence the functional capacities of COVID-19 survivors negatively. It would lead to obstructions in engaging with previous activities of daily living (9).

Exercise treatment is one of the novel approaches to support individuals with loss of functional capacities, having limitations in activities of daily living (10). Quality of life and health behavior of the patients with COVID-19 would be improved by restoring disturbed functions due to coronavirus infection through physiotherapy interventions. However, there is limited access to physiotherapy and rehabilitation services during pandemic conditions because of lockdown, especially for infected patients. For increasing accessibility to physiotherapy and rehabilitation care, the World Confederation of Physical Therapy has published a report advising interventions via home-based exercise programs with telerehabilitation (11). Home-based exercise programs have been proven to be cost-effective and significantly increase the functional capacities of individuals regardless of coronavirus influence in a 4-6-week timeframe (12). Exercise will also help them to recover chronic stress associated with the pandemic disease. All these mentioned parameters together would support the improvement in the immune system of the COVID-19 survivors (13).

Although exercise training is one of the fundamental treatment approaches in improving the quality of life of COVID-19 survivors up to date there is limited published framework for a structured exercise program in the COVID-19 $(14,15)$.

Since the individual difference in functional levels and possible difference in the severity of coronavirus infection, COVID-19 survivors should be assessed individually before prescribing an exercise program via telerehabilitation. The eligible patients should be well-identified, all risk should be eliminated and a proper exercise program should be developed according to functional levels.

This document suggests a framework for physical therapists to put into practice an exercise training via telerehabilitation in COVID-19 survivors. The proposed framework has consisted of determination of eligible and risky COVID-19 patients for telerehabilitation intervention, physiotherapy assessment tools via telerehabilitation, 6-week exercise prescription based on FIIT-VP principle (frequency, intensity, time, type, volume, and progression) and criteria for ending exercise.

\section{METHODS}

This framework was suggested by searching reviews and original articles conducted in "Exercise and COVID-19" and "Exercise and Telerehabilitation" and in combination of both keywords in PubMed database.

\section{RESULTS}

\subsection{Exercise Prescription Via Tele Rehabilitation for COVID-19 Survivors}

\subsubsection{The eligible COVID-19 survivors for exercise program via telerehabilitation}

Expert opinion advises that patients with COVID-19 diagnosis should complete their medical treatment 14 days before participating in any exercise program (16).

\subsubsection{Risky groups for participating exercise via telerehabilitation in COVID-19}

Patients who were hemodynamically unstable and have percutaneous oxygen saturation $(\mathrm{SaO} 2)<95 \%$, fever $\geq 38^{\circ}$, stage 4 chronic kidney disease or need for dialysis, dyspnea> $3 / 10$ (according to BORG scale), fatigue level > 3/10 (BORG scale), unstable blood pressure (blood pressure $>140 / 90$ $\mathrm{mmHg}$ or $<90 / 60 \mathrm{mmHg}$ ), Stage 3-4 heart disease (according to the New York Heart Association), congestive heart failure, myocarditis, ventricular arrhythmia, ischemic/hemorrhagic stroke, pulmonary arterial hypertension, presence of neurodegenerative disease, increased risk for deep venous thrombosis or history for deep venous thrombosis, transplantation history, receiving immunosuppressive therapy, widespread malignancy, Mini-Mental State Examination (MMSE) score $<24$, advanced level of osteoporosis and fracture, being pregnant may not suitable for exercise program via telerehabilitation $(17,18)$.

\subsection{Designing an Exercise program via Telerehabilitation for COVID-19 survivors}

\subsubsection{Online Assessments}

Online assessments must be performed via easy, short, and simple assessment tools before participating in any exercise program. Table 1 suggests sample assessments that can be performed before prescribing an exercise program for COVID-19 survivors. These assessments include testing vital signs, physical activity level, exercise capacity, cardiopulmonary endurance, lower extremity functional muscle strength, depression, and anxiety level measurements.

Table 1. Online Assessment Tools

Vital signs: Heart rate, Blood pressure, Respiratory Rate, Fever Functional Exercise Capacity Tests

2 Minute Walking Test

10 Meter Walking Test

Time Up Go (TUG) test

Sit to Stand Test (Lower extremity functional strength)

Questionnaires

International Physical Activity Questionnaire - Short Form

EuroQoL-5D (EQ-5D)

Self-Anxiety Scale (1-4)

Self-Depression Scale (1-4) 


\subsubsection{Criteria for ending exercise}

Exercise sessions via telerehabilitation must be ended in case of an increase in heart rate above $85 \%$ of the predictive value, reduction in systolic blood pressure more than $20 \mathrm{mmHg}$, decrease in percutaneous oxygen saturation ( $\mathrm{SaO} 2$ ) $<93 \%$, increase in breathing frequency $>30$ breaths/ min, increased dyspnea, the onset of fatigue and pain, bradycardia, severe shortness of breath and feeling dizziness or lightheadedness, nausea or feeling sick, clamminess or sweating, chest tightness. Patients should be informed about these criteria and physiotherapists must be aware of checking these symptoms regularly (19).

\subsubsection{Exercise Prescription}

COVID-19 survivors have a different course of the disease since the virus can affect multiple systems in the body differently according to individual differences such as having comorbidity, smoking, and exercise habit and older age. Various effects of the virus may cause the COVID-19 survivors to have different exercise capacities following the infection.
Therefore, the classification of the patients according to their exercise capacity is an important approach before prescribing an exercise program. The Borg Scale is one of mostly used tool to measure overall exertion during physical activity. It is widely used to quantify perceived symptoms such as breathlessness and muscle fatigue during exercise (20).

It is suggested by the current paper to classify COVID-19 survivors into three categories such as being a sedentary or trained individual before COVID-19 diagnosis or being elder. Exercise capacity of individuals for both aerobic and resistance training are defined according to the modified Borg Scale (10 points) Baseline measurements would guide prescription of exercise program via telerehabilitation.

Six-week (three non-sequential exercise days per week) aerobic and resistance exercise program via Telerehabilitation is proposed according to the FITT-VP principle (Table 2 and Table 3). Stretching exercises are also included in the exercise design in the scope of warm-up and cool-down periods (2123).

Table 2. Aerobic Exercise Program for COVID-19 survivors

\begin{tabular}{|l|l|l|l|}
\hline Aerobic Exercise Training & Sedentary & Trained & Elderly \\
\hline Intensity / Severity & $\begin{array}{l}\text { Low (Borg 1-3) } \\
\text { Moderate (Borg 3-5) } \\
\text { High (Borg 5-8) }\end{array}$ & $\begin{array}{l}\text { Low (Borg 1-3) } \\
\text { Moderate (Borg 4-6) } \\
\text { High (Borg 6-10) }\end{array}$ & $\begin{array}{l}\text { Low (Borg 1-3) } \\
\text { Moderate (Borg 2-4) } \\
\text { High (Borg 3-7) }\end{array}$ \\
\hline Exercise Type & Walking & Walking & Walking \\
\hline Time & $30-60$ minute & $30-60$ minute & $30-60$ minute \\
\hline Frequency & $2-3$ day/week & 2-3 day/week & 2-3 day/week \\
\hline Total time per week & At least 150 minute & At least 150 minute & At least 150 minute \\
\hline Progression & $\begin{array}{l}\text { * Firstly increase in exercise time weekly } \\
\text { (approximately 10\%) }\end{array}$ & $\begin{array}{l}\text { * Firstly increase in exercise time } \\
\text { weekly (approximately 10\%) } \\
\downarrow\end{array}$ & $\begin{array}{l}\text { * Firstly increase in exercise time } \\
\text { weekly (approximately 10\%) } \\
\downarrow\end{array}$ \\
& $\begin{array}{l}\text { * Secondly upgrade in intensity according } \\
\text { to Borg Scale }\end{array}$ & $\begin{array}{l}\text { * Secondly upgrade in intensity } \\
\text { according to Borg Scale }\end{array}$ & $\begin{array}{l}\text { * Secondly upgrade in intensity } \\
\text { according to Borg Scale }\end{array}$ \\
\hline
\end{tabular}

Table 3. Resistance Exercise Program for COVID-19 survivors

\begin{tabular}{|l|l|l|l|}
\hline $\begin{array}{l}\text { Resistive Exercise } \\
\text { Training }\end{array}$ & Sedentary & Trained & Elderly \\
\hline Intensity / Severity & $\begin{array}{l}\text { Extremely easy (Borg 1) } \\
\text { Easy (Borg 2) Somewhat easy (Borg 3) } \\
\text { Somewhat hard (Borg 5) } \\
\text { Hard (Borg 7) } \\
\text { Extremely hard (Borg 10) }\end{array}$ & $\begin{array}{l}\text { Somewhat easy (Borg 3) } \\
\text { Somewhat hard (Borg 5) } \\
\text { Hard (Borg 7) } \\
\text { Extremely hard (Borg 10) }\end{array}$ & $\begin{array}{l}\text { Extremely easy (Borg 1) } \\
\text { Easy (Borg 2) } \\
\text { Somewhat easy (Borg 3) } \\
\text { Somewhat hard (Borg 5) } \\
\text { Hard (Borg 7) }\end{array}$ \\
\hline $\begin{array}{l}\text { Exercise Type: Number } \\
\text { of Sets / Number of } \\
\text { repetitions }\end{array}$ & $\begin{array}{l}\text { Squat: 1-2 sets, 10 reps } \\
\text { Push up: 1-2 sets, 10 reps } \\
\text { Sit-up: 1-2 sets, 15 reps } \\
\text { Walking lunges: 1-2 sets, 5 reps }\end{array}$ & $\begin{array}{l}\text { Squat: 2-3 sets, 20 reps } \\
\text { Push up: 2-3 sets, 20 reps } \\
\text { Sit-up: 2-4 sets, 20 reps } \\
\text { Walking lunges: 2-3 sets, 10 reps }\end{array}$ & $\begin{array}{l}\text { Squat: 1-3 sets } \\
\text { Push up } 12 \text { reps } \\
\text { Sit up: 1-3 sets, 8-12 reps } \\
\text { Walking lunges: 1-2 sets, 5 reps }\end{array}$ \\
\hline Frequency & 2-3 days / week & 2-3 days / week & 1-3 days/week \\
\hline Progression & $\begin{array}{l}\text { Firstly, the increase in the number of repetitions, } \\
\text { Secondly, the increase in intensity according to the Borg Scale }\end{array}$ & \\
\hline
\end{tabular}




\section{CONCLUSION}

Up to current knowledge, there is no published or suggested an exercise training framework for COVID-19 survivors. This paper would provide a sample exercise framework for physiotherapists who are willing to encourage their COVID-19 patients by means of regaining their functional capacities in their daily life. Moreover, this proposed exercise program via Telerehabilitation would also help them to overcome barriers to get face to face with their COVID-19 patients in the clinical environment during pandemic conditions.

This firstly announced exercise program via Telerehabilitation, actually at home, for COVID-19 survivors would also support public health by preventing crowded environments especially in health care centers.

\section{REFERENCES}

[1] World Health Organization. Clinical management of COVID-19: interim guidance. 2020 May 27. (Accessed:14.06.2020) Available from: URL: https://www.who.int/publications/i/ item/clinical-management-of-covid-19.

[2] T.C. Sağlık Bakanlığı Halk Sağlığı Genel Müdürlüğü. COVID-19 Rehberi. 2020 July 29. (Accessed: 31.06.2020) Available from: URL: https://covid19bilgi.saglik.gov.tr/tr/covid-19-rehberi. html

[3] Kakodkar P, Kaka N, Baig MN. A comprehensive literature review on the clinical presentation, and management of the pandemic coronavirus disease 2019 (COVID-19). Cureus 2020; 12.4 .

[4] World Health Organization. Coronavirus disease (COVID-19) pandemic 2020. Accessed:24.07.2020. Available from: URL: https://www.who.int/emergencies/diseases/novelcoronavirus-2019?gclid=EAlaIQobChMI6Nv8tLfm6gIVUe3tCh 2faQ6yEAAYASAAEgIBIPD_BwE.

[5] World Health Organization. Report of the WHO-China joint mission on coronavirus disease 2019 (COVID-19). Accessed:24.07.2020. Available from: URL: https://www. who.int/publications-detail/report-of-the-who-china-jointmission-on-coronavirus-disease-2019-(covid-19)

[6] Madjid M, Safavi-Naeini P, Solomon SD, Vardeny O. Potential effects of coronaviruses on the cardiovascular system a review. JAMA Cardiol 2020; 5(7):831-840.

[7] Spruit MA, Holland AE, Singh SJ, Troosters T. Report of an adhoc international task force to develop an expert-based opinion on early and short-term rehabilitative interventions (after the acute hospital setting) in COVID-/19 survivors. https:// ers.app.box.com/s/npzkvigtl4w3pb0vbsth4y0fxe7ae9z9. Accessed:24.06.2020

[8] Mao L, Jin H, Wang M, Hu Y, Chen S, He Q, Chang J, Hong C, Zhou Y, Wang D, Miao X, Li Y, Hu B. Neurologic manifestations of hospitalized patients with coronavirus disease 2019 in Wuhan, China. JAMA Neurology 2020; 77(6): 683-690.

[9] Cheval B, Sivaramakrishnan H, Maltagliati S, Fessler L, Forestier C, Sarrazin P, Orsholts D, Chalabaev A, Sander D, Ntoumanis $N$, Boisgontier MP. Relationships between changes in selfreported physical activity and sedentary behaviors and health during the coronavirus (covid-19) pandemic in France and Switzerland. SportRxiv 2020; 1-6.

[10] Pasanen T, Tolvanen S, Heinonen A, Kujala UM. Exercise therapy for functional capacity in chronic diseases: an overview of meta-analyses of randomised controlled trials. BJSM 2017; 51(20), 1459-1465.

[11] World Confederation for Physical Therapy. Information and resources about COVID-19. Accessed: 23.06.2020. Available From: URL: https://www.wcpt.org/news/Novel-Coronavirus2019-nCoV. 2020.

[12] Huang G, Ismail H, Murnane A, Kim P, Riedel B. Structured exercise program prior to major cancer surgery improves cardiopulmonary fitness: a retrospective cohort study. Support Care Cancer 2015; 24: 2277-2285.

[13] Laddu DR, Lavie CJ, Phillips SA, Arena R. Physical activity for immunity protection: Inoculating populations with healthy living medicine in preparation for the next pandemic. Prog Cardiovasc Dis 2021; 64: 102.

[14] Yang YC, Chou CL, Kao CL. Exercise, nutrition, and medication considerations in the light of the COVID pandemic, with specific focus on geriatric population: a literature review. J Chin Med Assoc 2020; 83(11), 977-980.

[15] Gonzalez-Gerez JJ, Bernal-Utrera C, Anarte-Lazo E, GarciaVidal JA, Botella-Rico JM, Rodriguez-Blanco C. Therapeutic pulmonary telerehabilitation protocol for patients affected by COVID-19, confined to their homes: study protocol for a randomized controlled trial. Trials 2020; 21(1), 1-9.

[16] Liang T. Handbook of COVID-19 prevention and treatment. The first affiliated hospital, zhejiang university school of medicine. Compiled According to Clinical Experience. 2020; 68.

[17] Liu K, Zhang W, Yang Y, Zhang J, Li Y, Chen Y. Respiratory rehabilitation in elderly patients with COVID-19: a randomized controlled study. Complementary Therapies in Clinical Practice 2020; 39:101166.

[18] Lau MC, Ng YF, Jones YM, Lee WC, Siu HK, Hui SC. A randomised controlled trial of the effectiveness of an exercise training program in patients recovering from severe acute respiratory syndrome. J Physiother 2005; 51:213-219.

[19] World Health Organization Regional Office for Europe. Support for rehabilitation: self-management after COVID-19. Related Illness 2020; Accessed:05.07.2020 Available from: URL: https://www.who.int/publications/m/item/support-forrehabilitation-self-management-after-covid-19-related-illness.

[20] Mador MJ, Rodis A, Magalang UJ. Reproducibility of borg scale measurements of dyspnea during exercise in patients with COPD. Chest, 1995, 107.6: 1590-1597.

[21] World Health Organization. Global recommendations on physical activity for health. 2010. Accessed 22.06.2020. Available from: URL: https://apps.who.int/iris/bitstream/ handle/10665/44399/978.924.1599979_eng.pdf?sequence=1

[22] World Health Organization. Physical Activity. 2020. Accessed: 22.06.2020. Available from: URL: https://www.who.int/newsroom/fact-sheets/detail/physical-activity.

[23] Hammami A, Harrabi B, Mohr M, Krustrup P. Physical activity and coronavirus disease 2019 (COVID-19): specific recommendations for home-based physical training. Managing Sport and Leisure 2020, 1-6. 